\title{
Biblioteca e desenvolvimento sócio-econômico: um desafio para os profissionais da informação
}

\author{
SuELI ANGELICA Do AMARAL \\ Departamento de Ciência da Informação e D ocumentação \\ da Universidade de Brasília, Brasil, SSQN 211 \\ Bloco J ap. 105 70863-100 \\ Brasilia-D F-Brasil
}

\begin{abstract}
RESUMEN
El texto destaca la información como recurso para el desarrollo social y económico, y muestrala importancia que tiene la biblioteca como organización esencial para la efectiva promoción del desarrollo de la sociedad. También enfatiza la adopción de técnicas de mercadotecnia como medio para que las bibliotecas alcancen el éxito en la efectiva participación y con ello garanticen su futuro. Finalmente subraya el reto que tienen los profesionales de información como agentes del desarrollo social.

\section{LIBRARY AND SOCIAL ECONOMCDEVELOPMENT: A CHALLENGE FOR INFORMATION PROFESSIONALS SUELI ANGELICA DO AMARAL}

ABST RACT

The next highlights information as a resource for social and economic development. It shows the importance of libraries, as an essential organization, with effective participation to promote the society development. It also emphasizes the adoption of marketing techniques, as a means for librries to succeed in this effective participation and in guarenteing their future. Finally, it stresses the challenge of the role of information professionals as agents for social development.
\end{abstract}
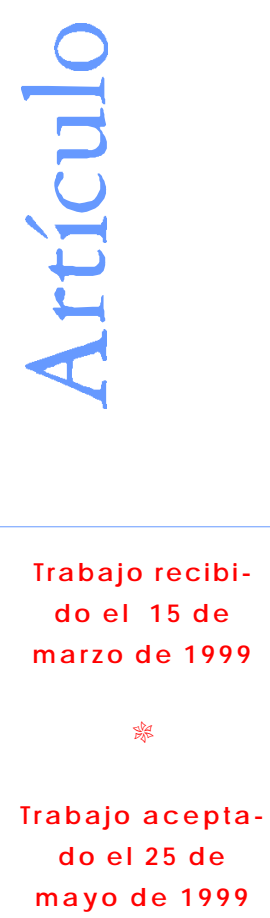

\section{IN FO RMAÇÃO E DESEN V OLVIMENTO SÓCIO-ECONÔNOMICO}
A lterações na estrutura da economia de um país são propostas para que seja al- cançado o seu desenvolvimento econômico, mas éfundamental que este desen- volvimento seja acompanhado pela melhoria do padrão de vida da população, pois só dessa forma é atingido o desenvolvimento social.
A O rganização das Nações Unidas usa como indicadores do grau de desenvolvi- mento dos países: o índice de mortalidade infantil, esperança de vida média, grau de 
dependência econômica externa, nível de industrialização, potencial científico e tecnológico, grau de alfabetização/ instrução e condições sanitárias.

Entre os obstáculos a serem vencidos, portanto, estão as dificuldades de toda população integrar-se na economia nacional; o isolamento social, cultural ou econômi$\mathrm{co}$, representado por barreiras lingüísticas e religiosas entre os diferentes setores da população e por subsistemas econômicos alienados do conjunto da economia nacional; a dificuldade de encaminhamento do excedente potencial da economia para os setores prioritários; o desperdício de recursos que, investidos poderiam reproduzir-se e ampliar (Sandroni, 1994).

Como desenvolver qualquer atividade ou empreendimento para vencer essas barreiras, qualquer que seja o cenário de trabalho sem dispor de informações? Portanto, a informação será o insumo de fundamental importância de geração de conhecimento, que impulsionará o desenvolvimento da sociedade.

Masuda (1982) adverte que passamos da era agrícola para a era industrial e hoje vivemos numa sociedade pós-industrial. Para ele, assim como a unidade fundamental na era agrícola foi a propriedade agrícola e na era industrial a fábrica assumiu destacada importância, na sociedade pós-industrial a informação passa a ser o insumo básico para o desenvolvimento. Essa abordagem empresta uma importância relevante à unidade de informação, seja ela denominada biblioteca, (como neste trabalho), centro/ serviço/ departamento/ setor de documentação/ informação, ou qualquer outra designação, segundo sua atuação ou extensão.

Na opinião de Vitro (1988), que acumulou conhecimentos para estabelecer as diferenças entre os países desenvolvidos e os do Terceiro Mundo, o setor de informação, chamado por ele de setor informativo, é constituído pelos serviços de informação, desde a área de rádio e televisão, passando pelo videotexto, jornais, revistas, bancos, empresas de exportação, firmas de consultoria, setores beneficiados pelo progresso na área de informática e incluindo também as bibliotecas. Robert Vitro considera que o setor informativo foi, é e continuará sendo o ponto chave, que sustenta a transformação social e econômica através da ampliação das capacidades produtivas e consumistas dos recursos humanos. Segundo o autor, melhorar a capacidade de consumo aponta para que cada ser humano tenha os recursos econômicos para tomar decisões que lhe permitam satisfazer suas necessidades básicas. Isto não significa promover o consumismo, mas sim defender a possibilidade de todos os seres humanos terem acesso aos recursos econômicos para construírem seus destinos.

Vitro (1988) afirma que a informação custa dinheiro para as empresas, mas os bons empresários logo percebem que esse investimento acaba garantindo melhor lucro, a partir do momento em que influi para o crescimento da produção. Ele considera o setor informativo este mecanismo social. Segundo ele, quanto mais cresce 0 setor informativo, maior fica a capacidade do país ou de uma pessoa para agregar valor a seus próprios recursos.

Portanto, os profissionais da informação precisam estar preparados para enfrentar essa situação. Eles devem conscientizar-se do valor da informação para o 


\section{2}

desenvolvimento, em função das mudanças sofridas pela sociedade. Mas, será que eles se dão conta da dimensão do desafio profissional a que estão submetidos, quer queiram quer não?

\section{INFORMAÇÃO E DESAFIO PROFISSIONAL}

O profissional que lida com a informação precisa saber que a informação não pode ser considerada apenas como um bem econômico, uma vez que não se limita a ser um produto de matéria prima doméstica. Ela deve ser observada sob o ponto de vista de Masuda (1982) como um produto nacional de bem estar público, com todas as suas características relacionadas à produção, disseminação, desenvolvimento, informatização e poder.

A informação deve ser estudada como o fator essencial que permitirá o "salto" para a verdadeira transformação da sociedade. 0 conceito de informação evoluiráa medida que evoluir o conceito de consciência coletiva da sociedade. Isto porque, quando uma sociedade evolui, ocorre a transformação advinda da mudança de foco em relação aos fatores de produção e desenvolvimento econômico. A base dessa transformação é que o setor de informação, onde se inserem as unidades de informação, é intensivo em conhecimento e não em mão-de-obra. $O$ valor agregado do conhecimento ou do segmento tecnológico é progressivamente mais importante e incorporado ao bem, provocando a transformação industrial da matéria-prima pelo valor agregado (Botelho \&al., 1994).

Entre as habilidades exigidas para os profissionais da informação, principalmente os que lidam com a informação automatizada, Blaise Cronin (Cronin, 1992), em conferência proferida durante o Simpósio Internacional sobre a informação no terceiro milênio, em Belo Horizonte, em novembro de 1992, ressaltou a necessidade de desenvolver as habilidades interpessoais e de comunicação, acima das habilidades técnicas. Segundo Cronin, essas habilidades são consideradas importantes em função da relevância do saber como conhecer o comportamento dos usuários em relação à busca e uso de informação. D aí, o conferencista destacar a ênfase que deve ser dada à administração dos recursos disponíveis. Além disso afirma que as informações precisam ser confiáveis. Nesse sentido, para ele valerá a qualificação e a competência individual de cada profissional.

Se as bibliotecas estiverem interessadas em satisfazer as necessidades de informação de seus usuários, os profissionais da informação precisam se preocupar com o constante aprimoramento do desempenho do setor de informação. Não bastará pensar em métodos e técnicas. Será preciso, antes de mais nada considerar os recursos humanos. Portanto, sendo os profissionais da informação os responsáveis pelo setor de informação, cabe a eles a responsabilidade de buscar a melhor maneira de atender às necessidades de informação dos usuários. 
Sob esse aspecto torna-se importante a preocupação com a educação continuada, de toda a equipe da biblioteca, inclusive a do gerente. É preciso que haja um plano de desenvolvimento de recursos humanos que favoreça a participação em eventos, e em especial cursos, treinamentos, visitas e estágios, que favoreçam a atualização e o domínio das habilidades exigidas para o exercício profissional.

Quando as bibliotecas não eram automatizadas, muitos usuários preferiam manter seus arquivos pessoais para buscar informações de seu interesse, quando não confiavam na biblioteca. Hoje, os microcomputadores permitem o acesso aos mais diversos acervos estejam eles localizados em continentes os mais distantes de onde estiver o usuário interessado, desde que ele se disponha a utilizar as tecnologias disponíveis para resolver seus problemas, podendo fazêlo de modo confortável, muitas vezes de suas próprias residências, sem nenhuma interferência da biblioteca ou do profissional da informação.

Embora a adoção denovas tecnologias pelas bibliotecas seja essencial, vista desta maneira, não é simplesmente automatizando serviços que a biblioteca passa a atender satisfatoriamente seu público.

No cenário em que atuar, a biblioteca continuará a disputar seu espaço de sobrevivência junto aos seus concorrentes, mesmo quando dispuser de produtos e serviços de informação automatizados. 0 que ela precisa realmente, é conhecer os seus usuários para atendê-los em função das atividades que esses usuários desempenham, seus desejos e percepções relativos às necessidades informacionais. Para tanto, será preciso promover o encontro, mutuamente satisfatório entre essas necessidades, desejos e expectativas do mercado que a biblioteca precisa atender e os objetivos organizacionais de longo prazo da própria biblioteca e da organização a que esteja subordinada.

Essas atividades consistem no equilíbrio entre o interesse do mercado e o que a biblioteca pode oferecer. Nesta perspectiva, a prestação dos serviços de informação deveria ser considerada a partir da visão da biblioteca sob a ótica mercadológica. A aplicação das técnicas de marketing no setor de informação permitirá que a biblioteca seja encarada como um:"negócio". Essa abordagem pode auxiliar o profissional da informação a vislumbrar a dimensão da biblioteca e dos serviços prestados pelos profissionais da informação no desenvolvimento da sociedade.

Marketing pode ser visto como um processo gerencial, valorizando as trocas voluntárias de valores para garantir a so brevivência das organizações, sendo entendido como uma combinação de técnicas, cuja aplicação visa o perfeito processo de troca, beneficiando todos os elementos que nela interagem. 0 marketing permitirá que na relação de troca a necessidade não satisfeita de uma das partes seja atendida pelas condições oferecidas pela outra parte, mediante uma negociação estabelecida entre elas. D a dimensão filosófica da conceituação adotada dependerá o tipo de orientação de uma organização.(Amaral, 1990) 


\section{Investigadón Biblictedógica v. 13 No. 26 enem/ junio de 1999}

Q uando a biblioteca está orientada para o marketing, sua filosofia de atuação se volta para 0 atendimento, com ênfase na função de troca, mediante ações administrativas visando os objetivos organizacionais.

0 profissional da informação deve estar atento, percebendo que a disseminação das técnicas mercadológicas poderá contribuir para a efetiva mudança de atitude profissional, pois representa uma oportunidade de inovação. A opção pela orientação de marketing na administração das bibliotecas propiciará que os recursos sejam melhor aproveitados, incluindo-se nesse contexto o aproveitamento máximo da potencialidade das novas tecnologias disponíveis para a captação e recuperação da informação.

O papel do gerente da biblioteca adquire uma perspectiva importante na adoção do marketing. Sua capacidade gerencial assume posição de destaque na medida que sua atuação influencia a equipe sob sua responsabilidade. É o gerente que transmitirá ao seu pessoal a necessidade do engajamento de cada um na sua tarefa. Assim, 0 conceito ou mentalidade de marketing adotado como filosofia de atuação da biblioteca provavelmente adquirirá sua importância na mesma proporção em que for assumido pelo próprio gerente, refletindo a filosofia adotada pela biblioteca.

Portanto, éinteressanterefletir so bre as vantagens do marketing como ferramenta gerencial para melhorar o desempenho da biblioteca, contribuindo para que esta cumpra satisfatoriamente o seu papel de organização essencial para o desenvolvimento social, econômico, político e cultural da sociedade.

Assim, a adoção das técnicas mercadológicas deveria merecer atenção dos profissionais da informação, ainda que não seja esta a única alternativa para 0 aprimoramento da prestação dos serviços de informação pelas bibliotecas, considerando a perspectiva de sucesso comprovada na literatura biblioteconômica.

0 marketing é um processo gerencial, que implica em atividades de troca com ênfase no mercado. Isto determinará mudanças, que precisam ser planejadas, pensando-se nabiblioteca como um "negócio", onde o impacto das novas tecnologias envolva todos os aspectos sociais, econômicos, políticos, culturais, legais e éticos, que interferem na responsabilidade dos profissionais da informação em relação à sociedade.

\section{¿COMO O MARKETING PODE AJUDAR?}

É preciso saber como fazer a transposição dos conceitos mercadológicos utilizados pelo setor lucrativo, adaptando-os ao uso pelas bibliotecas. Nesse âmbito, a transposição conceitual é recente e se constitui em um desafio para os profissionais da informação.

As razões apontadas para a adoção do marketing evidenciam a constante necessidade de incutir o verdadeiro profissionalismo naqueles que trabalham em bibliotecas, reconhecendo a importância dainformação como insumo básico das atividades 
desenvolvidas, sem descuidar da prioridade que deve ser dadaao usuário como consumidor dos produtos e serviços oferecidos nessas organizações. Trata-se de um profissionalismo caracterizado pela postura de respeito às atividades desenvolvidas, entendendo o verdadeiro papel social, político, educacional, informacional e cultural do profissional da informação, que vai além da preocupação com as regras do processamento técnico, sem menosprezá-las. Reconhece a necessidade do tratamento eficiente da coleção, focalizando prioritariamente o usuário.

A adoção do marketing em bibliotecas é vista como uma forma de valorizar o profissional da informação, melhorando a sua imagem mediante o uso aprimorado detécnicas para fazer trocas adequadas, quebrando as barreiras na comunicação entre bibliotecas e usuários para melhor satisfazer as necessidades informacionais desses usuários.

Weingand (1995) defende que o efetivo uso das estratégias de marketing pode ser a solução para o sucesso das unidades de informação de hoje, repensando-se suas posições e adaptando suas operações para um funcionamento efetivo em um novo ambiente em tempos de restrições econômicas, mudanças sociais, inovações tecnológicas. A autora alerta que quando essas forças atingem a estabilidade financeira e social, os executivos aprendem rapidamente a analisar onde o dinheiro está sendo gasto e que tipo de gastos podem proporcionar maiores benefícios. Em tempos passados, o suporte financeiro às unidades de informação era baseado em princípios diferentes. Referindo-se ao contexto americano, Weingand afirma que historicamente, bibliotecas públicas, universitárias, escolares e especializadas foram consideradas "boasccisas".

A interpretação da afirmativa da autora pode ser considerada também no contexto de outros países, se imaginarmos que mesmo tendo adquirido diferentes posições em diferentes contextos, historicamente, gastar com bibliotecas pode ser considerado um gasto necessário, que pudesse dispensar grandes explicações, exigências ou justificativas por tratar-se de causa justa.

Weingand, continuando sua análise do contexto americano, admite que hoje as bibliotecas se defrontam com a situação de precisarem ter subscrições da comunidade para so breviverem, permitindo que grupos de colaboradores possam cooperar propiciando condições impossíveis de serem assumidas individualmente, levando as bibliotecas a gostarem dessa relação positiva e confortável com seus usuários. Entretanto ela ressalta o quanto é difícil sustentar esse tipo de relacionamento.

Basicamente, a adoção de práticas mercadológicas implica em mudanças e por isso enfrenta barreiras. As pessoas resistem ao novo, pois não querem aceitar nada que as ameacem. Elas tendem a olhar apenas para o quelhes convém, rejeitam as novidades, pois têm medo de perder o que já conquistaram. A falta de conhecimento ou a falta de controle da nova situação pode causar insegurança. Algumas pessoas sentem necessidade de reagir contra, outras têm medo de assumir responsabilidades (Amaral, 1992). 


\section{Investigacón Biblideedógia v. 13 No. 26 enem/ junio de 1999}

Para minimizar esses obstáculos, antes de tudo é preciso analisar o ambiente em que a mudança ocorrerá, em função dos objetivos pretendidos. Ao planejá-la, deve-se saber como evidenciar os benefícios que ela acarretará.

Adotar marketing é assumir grande compromisso, que mudará a filosofia de trabalho, exigindo novas abordagens de planejamento. Certamente serão reveladas as deficiências no desempenho, as falhas de rotina, as políticas obsoletas, surgindo conflitos inesperados. Isto porque, a mudança é difícil e encontra resistência para derrubar hábitos consolidados.

Esseprocesso élongo. É preciso conhecer a cultura organizacional da instituição mantenedora da unidade de informação. Muitas vezes não há planejamento nessas organizações. É importante, por isso, considerar, tanto as forças diretivas quanto as restritivas às mudanças, para melhor aproveitá-las ou enfrentá-las.

Para reduzir a resistência podem ser tomadas algumas providências, de ordem geral, aplicáveis em qualquer biblioteca, como:

* solicitar ajuda de especialistas que possuam o perfil indicado para elaborar o diagnóstico da situação, avaliando como se deve agir para implantar 0 marketing;

* envolver as pessoas-chave da instituição no processo dessa mudança;

* compreender em que direção os esforços precisam ser empreendidos;

* visualizar, antecipadamente, a reação das pessoas às mudanças com a estimativa dessecomportamento de resistência, procurando-se saber como elas reagiriam em relação à mudança a ser proposta;

* notificar as pessoas envolvidas no processo sobre os fatos, as necessidades, os objetivos e prováveis efeitos da mudança.

E ssas medidas requerem constante observação e muito diálogo com as pessoas que trabalham nas bibliotecas. É importante que o objetivo da mudança seja definido. Todos devem entender o quanto a adoção do marketing contribuirá para melhorar o desempenho da organização. Para tornar claro esse propósito, os benefícios advindos da adoção devem ser destacados. São eles:

* aprimoramento e intensificação do relacionamento com o usuário;

* valorização do interesse pela satisfação dos usuários;

* ajustamento de produtos e serviços às necessidades informacionais dos usuários;

melhor direcionamento dos recursos financeiros destinados às bibliotecas, em função do ajustamento às necessidades dos usuários;

* maior estímulo àutilização dos serviços eà procura pelos produtos de informação oferecidos;

* atração de um maior número de usuários;

* maior divulgação das bibliotecas e dos recursos informacionais que elas dispõem;

* melhor imagem das bibliotecas e dos profissionais que atuam no setor; 
* maior apoio financeiro às atividades das bibliotecas pelos mantenedores.

O comprometimento do marketing com o planejamento estratégico surge com a necessidade em visualizar as mudanças para, antecipadamente, serem melhor administradas, utilizando-se inclusive as técnicas de análise ambiental.

D eacordo com Cronin (1982), marketing significa fazer as perguntas certas sobre:

* os objetivos da biblioteca e da prestação dos serviços;

* as características da população usuária;

* a qualidade da oferta;

* os benefícios proporcionados à clientela.

Por isso marketing necessita planejamento, comunicação, treinamento para 0 atendimento e gerência efetiva, entre outros requisitos. Isto significa mudança do comportamento profissional e empenho para que o usuário adquira a confiança na prestação de um serviço de qualidade, que comprometefavoravelmente a reputação e a imagem do setor de informação.

É preciso sair do imobilismo, levantar da cadeira, sair do escritório, abandonar o acervo só de livros, negligenciar rotinas tradicionais e práticas antiquadas em favor do espírito de descoberta do mundo dos usuários, com flexibilidade de atitudes.

A adoção do marketing deve permitir a manutenção ecadavez maior alocação de recursos financeiros, alcançando a satisfação dos usuários e mantendo satisfeita a equipe de trabalho.

É importante porém que não seja prometido aquilo que não pode ser oferecido, pois a expectativa frustrada é motivo de perda de credibilidade.

Afinal, é preciso considerar a biblioteca como uma empresa, pensando em informação como bem a ser comercializado. Isto não impedirá que os usuários sejam bem atendidos e recebam as informações que necessitam. É preciso conhecer os competidores da biblioteca e o meio ambiente em que ela está inserida.

Independentemente do tipo de biblioteca que seja considerado, ela deve ser vista como um "negócio", igual a outro qualquer, guardando-se suas específicas peculiaridades. Se os bibliotecários agirem dessa maneira, poderão com maior facilidade se lecionar as oportunidades para agir e antecipar-se com as informações do interesse de seus usuários. Conseqüentemente, alcançarão resultados positivos, satisfazendo a contento as necessidades de informação desses usuários e fazendo melhor uso dos recursos disponíveis, esteja a biblioteca localizada em qualquer região do mundo.

O utro ponto a considerar é o caráter ético do marketing, que deve estabelecer princípios e limites de sua atuação, de forma consciente, respeitando o consumidor, comumente conhecido nas bibliotecas por usuário, e o meio ambiente. É a sua responsabilidade social apregoada pelos autores que o defendem daqueles que pretendem rotulá-lo como anti-ético e ofensivo.

Se não houver preocupação com o interesse da clientela/ usuários, de nada adiantará o avanço tecnológico. O s produtos e serviços automatizados precisam respeitar e entender as necessidades e exigências de qualidade, confiabilidade, respeitando as 
peculiaridades específicas de cada comunidade. A adoção das novas tecnologias deverá trazer consigo a preocupação social, econômica, política, cultural que precisa ser discutida pelos profissionais da informação.

\section{QUESTÕES SOBRE OS PROFISSIONAIS DA INFORMAÇÃO E O MARKETING}

Se as bibliotecas devem ser consideradas como um "negócio" e a terminologia mercadológica deve ser assimilada pelos profissionais da informação, de modo que a negociação com os mantenedores seja efetiva e a análise do contexto onde atuam possa ser realizada satisfatoriamente, será que os profissionais sabem em que "negócio" estão?

Alguns questionamentos devem ser feitos:

* os profissionais da informação reconhecem a importância do conhecimento das técnicas de marketing aplicadas às bibliotecas?

- As universidades preparam devidamente esses profissionais para o mercado de trabalho, de modo que eles estejam aptos a assumir suas responsabilidades no setor de informação ou gerenciar bibliotecas?

* D e um modo geral, as bibliotecas são vistas como um "negócio", onde existem clientes, consumidores, e usuários interessados em produtos ou serviços que satisfaçam suas necessidades de informação?

* Se os profissionais se dão conta dos avanços tecnológicos que permitem em poucos instantes pesquisar informações de infinitos acervos de documentos armazenados em suportes cada vez mais sofisticados, menores e com maior capacidade de armazenamento, será que dimensionam proporcionalmente a sua responsabilidade para:

- assegurar o apoio financeiro da instituição mantenedora da biblioteca;

- encorajar e estimular o uso dos recursos informacionais disponíveis;

- preocupar-se com a satisfação das necessidades de informação dos usuários;

- intensificar e aprimorar seu relacionamento com a clientela, fornecedores, mantenedores, concorrentes e melhorar o atendimento de seus usuários;

- divulgar a biblioteca, seus produtos e serviços? (A maral, 1993)

Ficam os questionamentos para a discussão. As respostas podem ser controvertidas e as opiniões divergentes, mas precisam ser encontradas! É nossa responsabilidade!

Muitos profissionais da informação já estão conscientes de sua responsabilidade no negócio da informação, seja ela manual ou automatizada. Alguns se preocupam em divulgar os produtos e serviços que a biblioteca oferece, mas é preciso entender que o marketing vai além da divulgação. É preciso conhecer melhor os usuários como consumidores de informação para atendê-los satisfatoriamente. Afinal, é por causa deles e para eles que a biblioteca existe e é em função deles que sobrevive. 
Conhecê-los, envolvê-los e atendê-los bem, só poderá contribuir para o reconhecimento da instituição biblioteca e do profissional da informação. Para que isto seja uma realidade, o profissional deverá interagir com outros profissionais, somando esforços para melhorar seu desempenho e o da biblioteca.

A plicar técnicas de marketing pode ser uma alternativa de solução para otimizar os recursos disponíveis, alcançando os objetivos e resultados esperados, por meio de uma estratégia de ação efetiva. Esta estratégia deve atender à demanda social da sociedade, considerando os próprios valores do contexto em que ela se insere, sem perder de vista a totalidade do ser humano.

0 perfil político dainformação, por essa razão, está se tornando cada vez mais intenso. O s países podem ser classificados de acordo com a qualidade e quantidade de informação que possuem. Com base nessa premissa, os países classificados como "ricos em informação" têm o poder não somente da tecnologia do processamento da informação, mas também da sua geração.

As questões políticas, econômicas e sociais envolvidas são de difícil solução nesse impasse da dependência tecnológica, afetando a produção dos menos favorecidos. D e fato, todos os países do mundo estão preocupados com a política econômica da informação, tanto os países desenvolvidos quanto os em desenvolvimento. Entretanto, os países desenvolvidos consideram a informação como insumo indispensável para o desenvolvimento tecnológico e econômico, entendendo a informação como um produto negociável no mercado internacional, reconhecendo que um país incapaz de prover informação para seus cidadãos e indústrias perderá grande parte de sua autonomia, ficando à mercê das informações oferecidas pelos demais países. D essa forma, no mundo atual, a informação adquire o status de mercadoria e pode ser vendida de acordo com as leis de oferta e demanda que regem a comercialização de qualquer produto.

Na visão sistêmica da biblioteca, a informação é o insumo básico de entrada ao mesmo tempo em que se constitui no insumo básico de saída. Muitos fatores terão influência no ciclo documentário em cada biblioteca, de acordo com a sua tipologia e influência das mudanças que são constantes em todos os cenários. Principalmente a tecnologia da informação disponibiliza uma diversificação de avanços tecnológicos que permitem a proliferação de mecanismos os mais diversos e sofisticados para a captação, seleção, aquisição, produção, disseminação e recuperação de informações, em ritmo acelerado. 0 ciclo documentário setorna um diverso e encantado mundo, onde há muito a ser explorado pelas bibliotecas.

\section{TENDÊNCIAS FUTURAS}

Qualquer tipo de biblioteca, inclusive e principalmente, a biblioteca eletrônica ou virtual pode adotar as técnicas mercadológicas. Seria até um absurdo, imaginar-se que biblioteca do futuro não admitisse sua concepção administrativa com a orientação mercadológica, quando o marketing apresenta toda uma perspectiva de visão futurística. 


\section{InvestigacónBiblictedóǵca v. 13 No. 26 enero/ junio de 1999}

Ainda que o marketing não seja a tábua de salvação para todos os males, nem a panacéia para curar todas as mazelas, a visão mercadológica da biblioteca só poderá contribuir para o melhor desempenho desse tipo de organização. Esta concepção levará o profissional da informação a olhar o futuro, questionando os problemas do passado e do presente, visando obter sucesso.

Em tempos de globalização da economia, política buscando novos caminhos calcados nos valores humanos, gestão da qualidade total, concorrência acirrada, privatizações, valorização do código de defesa do consumidor, aperfeiçoamento evolutivo das tecnologias aplicadas à informação, crescimento exponencial e obsolescência dainformação, necessidades de informação múltiplas e diversificadas dos usuários vale pensar no aperfeiçoamento das técnicas gerenciais dos recursos informacionais disponíveis, evidenciando as novas prioridades do marketing.

Também voltada para o futuro, a revista Marketing \& Negócios, ano 2, n.13 de julho de 1993, preocupada com o que pode acontecer com as empresas que não atentarem para os conceitos de globalização, qualidade e preservação do meio ambiente, publicou, na página 37, um quadro sobre as novas prioridades do marketing, como parte de artigo sobre as tendências para 0 ano 2000. Adaptando-se 0 quadro para 0 ambiente das bibliotecas, destacam-se os seguintes enunciados:

* investigar, permanentemente, os novos nichos de mercado dainformação;

* inovar as técnicas de segmentação de mercado;

* identificar o novo perfil do consumidor;

* buscar novos produtos que proporcionem vantagens em relação à concorrência;

* criar e manter serviços personalizados aos usuários/ clientes/ consumidores; posicionar produtos e serviços em condições compatíveis com a imagem da biblioteca;

* entender novos modelos de distribuição no ambiente eletrônico;

* conhecer o novo papel da comunicação, interagindo com os profissionais desta área;

* descobrir o modelo ideal para promover os produtos e serviços oferecidos;

* aprimorar o relacionamento com a clientela;

visualizar modalidades para estabelecer parcerias com a comunidade, governo, órgãos de classe e agências de fomento;

moldar um novo e atualizado profissional para o atendimento ao público;

* investir em controles para aprimorar desempenhos da equipe, do gerente e das metodologias de trabalho (Tendências, 1993). 


\section{CONSIDERAÇÕES FINAIS}

Seria loucura admitir que o simples fato de a biblioteca adotar técnicas de marketing resolveria todos os problemas de um país e conseqüentemente o seu desenvolvimento econômico e social seria alcançado. Mas com certeza, a contribuição da biblioteca será válida, quando forem fornecidas informações utilitárias atualizadas, confiáveis e adequadas à população, que permitam melhores condições de vida dos cidadãos.

Se como ponto de partida forem tomados como exemplos, alguns dos indicadores do grau de desenvolvimento dos países, adotados pela 0 rganização das Nações Unidas, mencionados neste trabalho, pode-se assegurar que melhores informações e maior participação da biblioteca pública junto às comunidades carentes, certamente contribuiria para o desenvolvimento, ainda que em pequena parcela, conforme as dificuldades de cada país. Isto porque, 0 índice de mortalidade infantil, a esperança de vida média e as condições sanitárias podem melhorar com a realização de efetivas campanhas de informação utilitária a comunidades carentes desenvolvidas pelas bibliotecas, mesmo quando outros obstáculos persistirem, impedindo que sejam alcançados os índices ideais previstos relativos aos indicadores apontados.

No caso do desenvolvimento científico e tecnológico, o papel das bibliotecas especializadas edos profissionais dainformação queatuam nesse âmbito éfundamental. Entre outras justificativas, porque o crescimento exponencial daliteratura técnico-científica mundial dificulta o processo da atualização profissional. Q ualquer profissional para se manter atualizado precisa obter a cada ano cerca de $20 \%$ de novos conhecimentos, só para compensar a perda e o desgaste naturais de sua capacitação técnica. Este fenômeno implica uma inevitável corrida para a atualização, que mal programada induzirá a pesquisas inúteis, duplicidade de esforços e gastos desnecessários na busca de informações já obtidas e utilizadas. Cada vez mais, a informação precisa e atualizada torna-se indispensável à realização de cada projeto. Por essa razão, as organizações técnico-científicas necessitam de um organismo que efetivamente selecione, capte, processe, armazene e divulgue satisfatoriamente as informações necessárias ao desenvolvimento de suas atividades, de modo que a re cuperação das informações ocorra em tempo hábil, satisfazendo efetivamente a demanda informacional específica de cada organização e de cada usuário.

A biblioteca especializada pode ser este organismo. Seja qual for sua área de atuação, desencumbir-se de missão tão complexa e relevante é essencial para o de senvolvimento da sociedade. D a mesma forma, em função dos modelos de desenvolvimento estabelecidos em cada país e de suas peculiaridades, a participação dessas bibliotecas pode ser maior ou menor, mas certamente terão sua parcela de responsabilidade, assumindo seu verdadeiro papel nesse contexto e contribuindo para oferta de infra-estrutura informacional adequada. 


\section{InvetigacónBiblictedóǵca v. 13 No. 26 enero/ junio de 1999}

Contribuir para o aumento do grau de alfabetização/ instrução também é tarefaa ser cumprida pelas bibliotecas escolares, guardando-se, do mesmo modo as dificuldades de cada país sob esse aspecto.

Trata-se da questão de o profissional de informação aceitar sua responsabilidade social de agente de transformação da sociedade, quedeve ser bem informada. É preciso ousar e utilizar a criatividade, liderança, capacidade de inovação.

Além disso, os profissionais da informação, excepcionalmente os gerentes, devem aprender a converter idéias em realidade. D evem ampliar a capacidade de dialogar, exercitando a argumentação, que facilita o processo de negociação, principalmente com os mantenedores da biblioteca.

A adoção da orientação administrativa das unidades de informação voltada para o marketing implica em mudanças. Será preciso que os gerentes das unidades de informação aumentem seus conhecimentos sobre marketing, compreendendo a importância de conhecer as necessidades e interesses informacionais de seus usuários, respeitando as opiniões, críticas, reclamações e sugestões apresentadas por eles. Marketing é um estilo gerencial que requer eficiência e eficácia em busca da efetividade. Para atingir seus objetivos será necessário que toda a equipe esteja engajada no processo da adoção desse conceito, quando a inovação surge com o interesse de oferecer o melhor serviço atendendo os interesses dos usuários e garantindo o futuro das unidades de informação.

Além de desenvolver essas habilidades, o profissional da informação terá que conhecer o cenário em que se insere ainstituição em que atua e sua respectiva unidade de informação. D e igual importânciaéo conhecimento da cultura organizacional da instituição. Entender o comportamento das pessoas envolvidas na hierarquia institucional também ajudará no processo de tomada de decisão, facilitando a adoção de um comportamento pró-ativo.

A consciência da responsabilidade profissional deve nortear o desempenho do profissional da informação de modo que as dificuldades a serem enfrentadas não desestimulem a busca do reconhecimento devido às bibliotecas, principalmente nos países em desenvolvimento, onde de um modo geral o setor de informação não recebe suficiente apoio governamental.

D e fato, se os profissionais da informação desejam o reconhecimento e o apoio governamental, devem atuar de modo a tornar cada vez mais efetivo o desempenho das bibliotecas, ampliando e melhorando a imagem das bibliotecas. Só assim conquistarão e manterão 0 respeito da sociedade e conseqüentemente receberão 0 apoio governamental.

O presentedesafia o futuro dos profissionais da informação Não importam as dificuldades a serem enfrentadas. Se elas existem, é preciso superá-las. Sair do imobilismo ésempre um bom começo. Caberá portanto aos profissionais dainformação a iniciativa de encontrar o caminho certo para conquistar o espaço que lhes couber.

0 caminho pode ser percorrido de várias formas, mas é preciso saber onde se quer chegar. 
Machiavelli afirmava que "não há nada mais difícil de assumir, mais perigoso de conduzir ou de êxito mais incerto, do que liderar a introdução de uma nova ordem de coisas, pois a inovação tem como inimigos todos os que se saíram bem sob as antigas condições e tem defensores tépidos nos que, talvez possam se sair bem sob as novas."

O desafio do profissional da informação é ser criativo, inovar e acreditar no futuro. Com certeza, acreditar no futuro sempre exigiráboa parcela de coragem eimunidade ao ceticismo.

\section{REFERÊNCIAS BIBLIOGRÁFICAS}

AMARAL, Sueli Angelica do. Marketing and Brazilian libraries. Intemational Joumal of InformationandLibrary Reerch v.4, n.2, p.115-126, 1992.

- - .OnmerkeingnaskiblicterasdeGeøiêniaseTemdogaMineal. Brasilia: Universidade de Brasília.D epartamento de Ciência da Informação, 1990. 248p. (Dissertação de Mestrado)

- - . Marketing e gerência de biblioteca. In: MARKETING emunidades deinformação, etudos brasilerros Compilado por Amélia Silveira e Sueli Angelica do Amaral. Brasília : IBICT , SENAI, 1993. p.315-324

BotelHo, Tania Mara, Baptista, Sofia G alvão, Amaral, Sueli Angelica do. Informaçãoesoiæelade uma sociedade inteligente em transformação? In: CONGRESSO LATINO-AMERICANO DE BIBLIOTECONOMIA E DocumentaÇÃo,2. Congresso Brasileiro de Biblioteconomia e D ocumentação, 17. Belo Horizonte, 1994. Anais db... Belo Horizonte : Associação dos Bibliotecários de Minas G erais , Escola de Biblioteconomia da UFMG, 1994. 808p., p.438-467

CRONIN, Blaise. New technology and marketing; the challenge for librarians. AsibProwedings vol.34, n.9, Sept. 1982, p.377-393.

- - . Tendênias dostar deinfomaçãa profissicnalização au prdetarização? Palestra proferida no Simposio Internacional sobre informação para o terceiro milênio, Belo Horizonte, 1992.

MASUD A, Y onej. A sociebdedainformaçãocomosocedadepósindustrial. Rio de Ja neiro : Editora Rio, 1982. 210p.

SANDRONI, Paulo. Nowo diacnánio de €onama. São Paulo : Ed. Best Seller, 1994. 375p,. p.95-96

TENDÊNCIAS para o ano 2000. Marketing\& Neeǵios, ano 2, n.13, julho 1993, p.37

VITRO, Robert. O starinfomativonodesenduimentoeconômicoesodal, 1988.

WEING AND , D arlene E. Preparing for the new millenium: the case for using marketing strategies. Library Trends,vol.43, n.3, winter 1995, p.295-317. 